\title{
Finding the Form of an Irregular Meshed Steel and Glass Shell Based on Construction Constraints
}

\author{
Sigrid Adriaenssens, M.ASCE${ }^{1}$; Laurent $\mathrm{Ney}^{2}$; Eric Bodarwe ${ }^{3}$; and Chris Williams ${ }^{4}$
}

\begin{abstract}
In the context of the search for an efficient structural shape to cover the Dutch Maritime Museum courtyard in Amsterdam, Netherlands, the authors briefly discuss the driving design factors that influenced the earliest glass roof coverings. The trends that emerged during the late 20th and early 21 st century in the design of skeletal steel glass shells are exposed. These design developments range from sculptural to geometric and structural intentions. The discussion of the competition design development of the Dutch Maritime Museum steel glass shell roof shows the quest for a structurally efficient catenary form based on a poetic geometric idea. This paper presents a construction-driven design methodology that slightly adapts the numerical form found catenary shape with the objective of achieving planarity in all the triangulated, foursided and five-sided mesh faces. The challenge of facet planarity is gracefully solved by an analytical origami approach and presented. This approach is compared with finding the Maxwell reciprocal network diagram. The final faceted shape shows elegance and structural efficiency. DOI: 10.1061/(ASCE)AE.1943-5568.0000074. @ 2012 American Society of Civil Engineers.
\end{abstract}

CE Database subject headings: Design; Steel; Glass; Historic sites; Roofs; Netherlands.

Author keywords: Shape; Conceptual design; Form finding; Steel glass shell; Historic courtyard; Planarity faces; Construction constraint; Maxwell reciprocal network.

\section{Introduction}

In the wake of the Industrial Revolution, glass metal structures appeared as a result of two factors: society's desire for green, quiet spaces in overpopulated cities, and the scientific emergence of new construction materials (glass and iron).

In the early nineteenth century, the first greenhouses with a glazed roof appeared as living spaces. Their tall construction and maintenance costs (because of the glass and the required heating system) made them style icons of the elite. Their curved shapes [(1) ridge and furrow e.g., Chatsworth, United Kingdom (built in 1834), and (2) vaulted, e.g., Kew, United Kingdom (built in 1844) (Kohlmaier and Von Sartory 1991)] allowed the sparse sunlight into the space and hit the citrus and lime trees (hence, the name orangery). Other varieties of tender plants, shrubs, and exotic plants were also housed in the orangery. The introduction of the palm tree, an impressive and prestigious plant with large religious significance, pushed the shape of the greenhouse further upwards.

In the middle of the nineteenth century, the development of greenhouse typologies was in full swing, and resulted in culture

\footnotetext{
${ }^{1}$ Assistant Professor, Dept. of Civil and Environmental Engineering, Princeton Univ., Princeton, NJ 08540 (corresponding author). E-mail; sadriaen@princeton.edu

${ }^{2}$ Partner, Ney and Partners, sa, Chaussée de la Hulpe 181, B-1170 Brussels, Belgium.

${ }^{3}$ Partner, Ney and Partners, sa, Chaussée de la Hulpe 181, B-1170 Brussels, Belgium.

${ }^{4}$ Senior Lecturer, Dept. of Architecture and Civil Engineering, Univ. of Bath, Claverton Down, Bath BA2 7AY, U.K.

Note. This manuscript was submitted on August 13, 2009; approved on October 3, 2011; published online on August 15, 2012. Discussion period open until February 1, 2013; separate discussions must be submitted for individual papers. This paper is part of the Journal of Architectural Engineering, Vol. 18, No. 3, September 1, 2012. CASCE, ISSN 1076$0431 / 2012 / 3-206-213 / \$ 25.00$.
}

houses, conservatories, and winter gardens [e.g., the Royal greenhouses, Laeken, Belgium (built in 1876) shown in Fig. 1 (Woods and Swartz 1988)]. The winter garden is of particular interest to this paper because it defines a social meeting place adjacent to a private mansion or public building.

Mass production of affordable iron in the second half of the nineteenth century further encouraged the design and construction of tall and large span exhibition halls made of cast and wrought iron and glass. Plenty of light entered the exhibition areas of buildings, such as the Crystal Palace, United Kingdom (built in 1851) (shown in Fig. 1). Its filigree iron structural skeleton was prefabricated, and it was subsequently dismantled and moved from Hyde Park to Sydenham in South London. Unfortunately, it was destroyed by fire in 1936.

The second half of the 20th and the early 21 st centuries experienced a new uprising of the design and construction of roofs over social gathering places, winter gardens without plants, covering courtyards of historically important public buildings [e.g., the great courtyard of the British Museum, United Kingdom; see Fig. 1; the Deutschen Historischen Museum, and Museum fur Hamburgische Geschichte, Germany (both Schlaich Bergermann and Partners, built in 2001 and 2004, respectively); and the Smithsonian Institute, Washington, DC (Foster and Partners, and Buro Happold in 2001)]. The shapes of these glass-covered, single-layered steel skeletal shells were driven by a combination of sculptural, geometric, physical, and constructional considerations (Williams 2000). The recent re-emergence of these structures goes hand in hand with the evolution of digital design tools that enable the designer to develop and analyze more free and daring geometries.

\section{Single-Layered Steel Skeletal Shells Covered with Glass}

Today's designers (either from an architectural or engineering background) of these nonbotanical winter garden shells seem to be guided by one or more of the following four driving factors: 

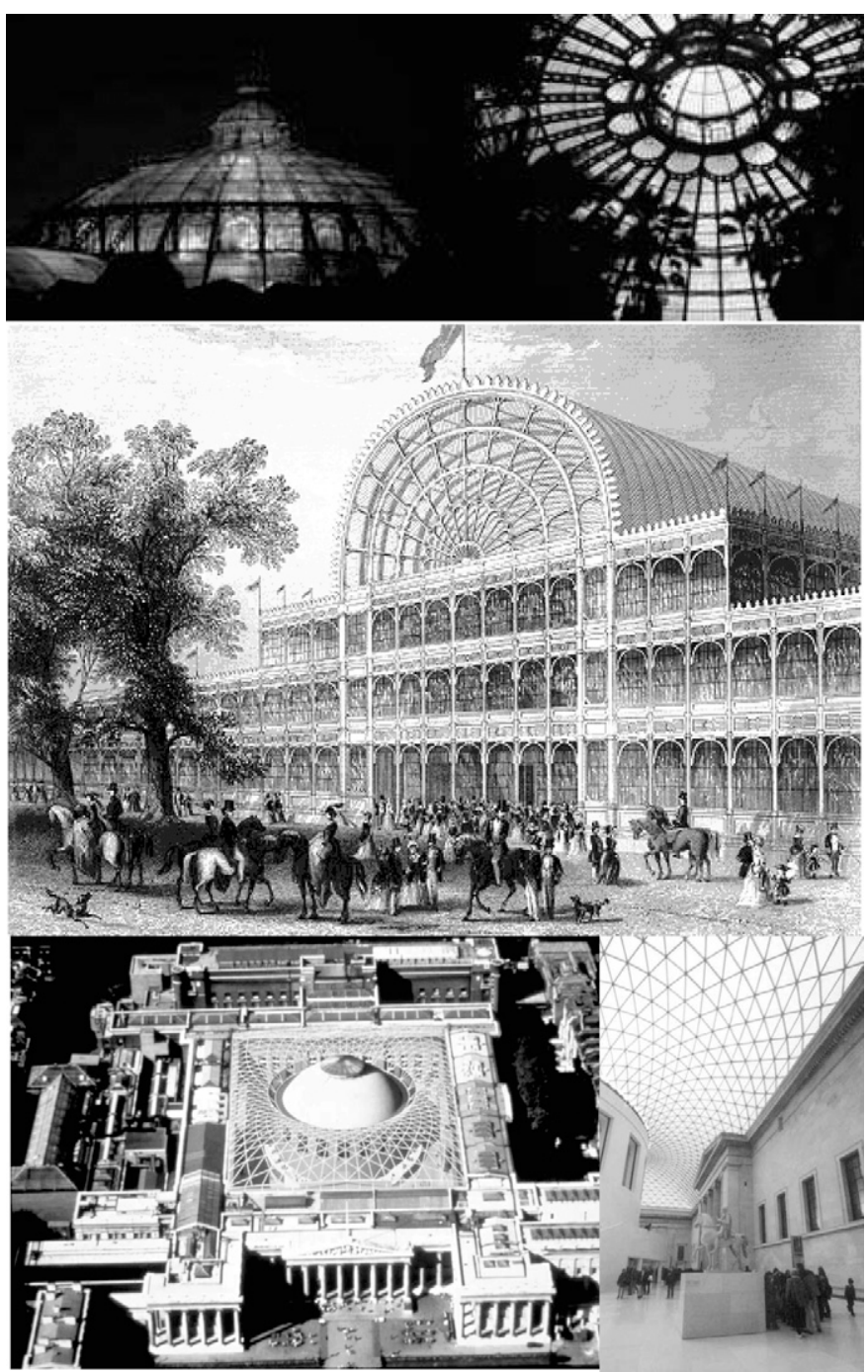

Fig. 1. (a) Laeken winter garden (Belgium, built in 1875) still serves as a social meeting place. (Jackson 2007; reprinted with permission from the photographer); (b) prefabricated Crystal Palace (United Kingdom, built in 1851) was dismantled soon after its intended use (reprinted from http://commons.wikimedia.org/wiki/File:Crystal_Palace.PNG, originally from Tallis' History and Criticism of the Crystal Palace. 1852); (c) British Museum Courtyard (United Kingdom, built in 2000) steel roof adds value to the museum by expanding the useable circulation space (image by authors)

imposed existing situation, sculptural architectural esthetics, geometric shape, and structural efficiency through form.

\section{Imposition on an Existing Situation: The Modern Winter Garden}

In the last two decades, existing historically relevant public buildings with a central open courtyard have been adapted to extend the useable floor area to an indoor/outdoor climate. These generally narrow buildings count on the courtyard for daylight. Steel and glass shells offer a unique solution to this design challenge. The historic context for these shells imposes a series of design constraints within which the designer has the freedom to develop the shell's form. The boundary conditions often include height restrictions and limits upon the maximum extra load that can be imposed on the existing building, particularly in a horizontal direction. The British Museum Court Roof is supported on sliding bearings so that no horizontal thrust is exerted on the historic masonry walls of the museum (Williams 2001). In the reviewing the design of recently realized steel shells, the driving design factor more often seems to be architectural scenographic esthetics rather than structural performance.

\section{Sculptural Architectural Esthetics}

With the available geometric digital modeling tools, more architects base their work on esthetic (and often subjective) considerations to achieve scenographic effects. This sculptural design intent can be appreciated for its inventiveness of plastic forms, but not for its consideration of gravity loads. This particular design approach thus raises questions from a structural point of view with respect to the resulting lack of structural efficiency. Unfortunately, the structural solutions necessary to make these sculptural shapes possible typically use an awkward and significant accumulation of material. These free-form shapes often lead to unfavorable internal forces and under loading do not allow membrane stresses to develop within the surface. These shapes then rely on bending action-the least effective of all basic load carrying methods. Designers often ignore the fact that the free form is made up of conventional constructional and structural means. Frank Gehry, the Pritzker prize-winning architect, promotes this architectural process, which expresses sculptural intentions but is disconnected from any sculptural intent (Shelden 2002). A rationalization is needed at the preliminary design stage that goes beyond this scenographic experience and concentrates on the structural integrity of the design (Leach et al. 2004).

The evolution of an initial sculptural shape into a constructable structure needs a strong team of engineers and contractors. For example, the conceptual design for the shell of the Nuovo Polo Fiera Milano, Italy (built in 2004) (Guillaume et al. 2005) was developed by the architect Massimiliano Fuksas and then handed over to the engineers Schlaich Bergermann and Partners and contractor Mero TSK Group for the development of the structural and constructional rationale for the project (see Fig. 2) (Basso et al. 2009).

\section{Geometric Shape}

Geometry is a tool that has been used since antiquity for the development of architectural shapes. These forms are thus limited by the rules imposed by analytical geometry and the designer's imagination. Through the centuries, architecture has developed around "simple" geometries chosen for their constructive or structural qualities. [Examples can be found in the design of the cupola of the cathedral Santa Maria del Fiore, Italy (built in 1436), by Filippo Brunelleschi and more recently the thin concrete shells by Felix Candela (Moreyra Garlock and Billington 2008).] Surfaces of revolution, translational surfaces, and scale-trans surfaces lend themselves excellently to shell action and discretization into subelements. In this context, the work of Jorg Schlaich and Hans Schober on steel shells is innovative. They devised a method to find the right translational or scale-trans surface that can be divided into four-sided planar meshes. The Hippo House of the Berlin Zoo, Germany (built in 1996), designed by architect Grieble and Schlaich Bergermann and Partners (Schober 2002, Glymph et al. 2004) exploits this approach in an elegant steel shell, as shown in Fig. 3.

\section{Structural Efficiency through Form}

Of all traditional structural design elements (ranging from material choice, profile sections, node type, global geometry, and support conditions), global geometry mostly decides whether a shell will be stable, safe, and stiff enough. The shell spans large distances with 


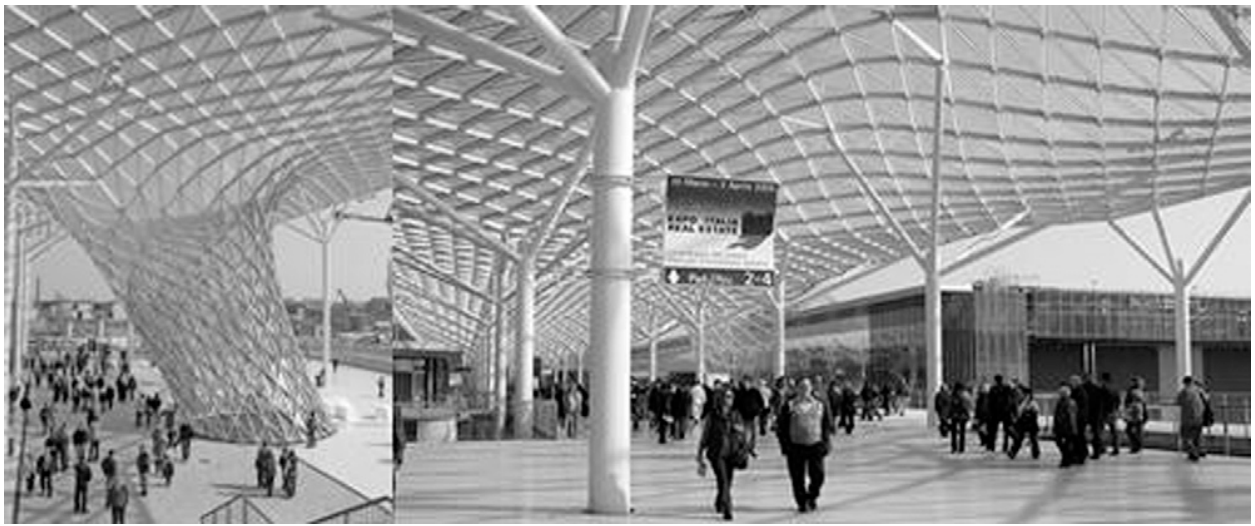

Fig. 2. Nuovo Polo Fiera Milano (Italy, built in 2004; architect Massimiliano Fuksas, structural engineers Schlaich Bergermann and Partner and Mero TSK Group) illustrates how a sculptural shell is discretized in four-sided and triangulated (at the supports) meshes

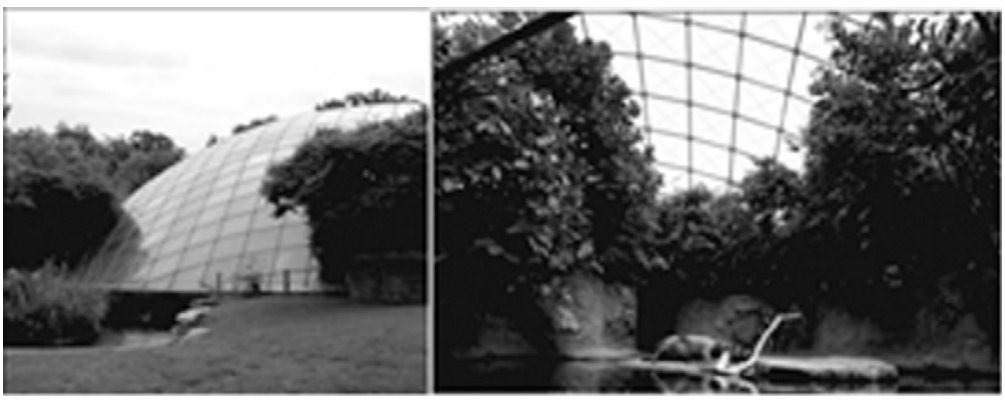

Fig. 3. Hippo House (Germany, built in 1997), designed by architect Grieble and Schlaich Bergermann and Partners, shows the discretization of a translational surface into planar quadrangular meshes (photograph courtesy of Edward Segal, reprinted with permission)

a fine structural network (skeleton) of individual small subelements. The first design consideration lies in setting the exact boundary conditions within which the shell shape can be developed. The curved shape is of vital importance to achieve stability through membrane stiffness. Shell bending needs to be avoided by finding the "right" geometry, so that under the self-weight only membrane action results. Membrane action makes efficient use of material. The important structural design challenge lies in the determination of a three-dimensional (3D) surface that will hold the skeletal shell. In the twentieth century, both architects and engineers [Gaudi (Huerta 2003), Otto (Otto et al. 1995), and Isler (Billington 2008)] experimented with physical form finding techniques, which for a given material, created a set of boundary conditions and gravity loading that found the efficient 3D structural shape. The importance of finding a funicular shape for steel shells lies in the fact that the self-weight (gravity loads caused by steel and glass) contributes largely to the load to be resisted. The subelements need to be loaded axially to make most efficient use of the section profile.

Numerical form finding techniques [force density (Schek 1974) and dynamic relaxation (Day 1965)] have been successfully applied to weightless systems whose shape is set by the level of internal prestress and boundary supports. However, when it comes to funicular systems whose shape is not determined by initial prestress but by gravity loads (such as the case for masonry, concrete, or steel shells), fewer numerical methods have been developed. This is mainly because of the difficulty of finding optimal forms for those shells that rely on both tensile and compressive membrane stresses to resist dead load. Kilian and Ochsendorf (2005) presented a shape-finding tool for statically determinate systems based on a particle-spring system solved with a Runge-Kutta solver, used in computer graphics for cloth simulation. Block and Ochsendorf (2007) published the thrust network analysis to establish the shape of pure compression systems. For the initial design competition for the Dutch Maritime Museum roof project, the dynamic relaxation method usually used for prestressed systems was adapted to deal with $3 \mathrm{D}$ funicular systems with tension and compression elements under gravity loads.

\section{Competition Design for a Steel Glass Shell over the NSA Courtyard}

The Dutch Maritime Museum planned a thorough museum renovation in the near future. The restricted space in the seventeenth century historic building hinders the movement of visitors. The courtyard needed to be integrated into the museum's circulation space, sheltered from weather, and kept to a minimal indoor temperature. An invited design competition was held for a new glass roof that added value to the historic building. In 2005, Ney and Partners, a Brussels-based engineering design consultancy, won this competition with a steel and glass shell design. The shell manufacturing and construction processes took place between 2009 and 2011. In 2012, the project was awarded the Amsterdam Architectural Prize.

\section{Initial Planar Geometry}

In the late seventeenth century, the historic building housing the museum (shown in Fig. 4) was the headquarters of the admiralship. 
It was the instrument and symbol of the Dutch maritime power. The development of this sea-faring nation was closely linked to the production of sea charts and the associated sciences, such as geometry, topography, and, astronomy. The classic building also uses geometry as a basis for design. The choice for the initial two-dimensional (2D) geometry of the glass roof tells the spectator a story about the building's history and its close relationship to the history of the sea. At the origin of this 2D geometry lies a loxidrome map with 16 wind roses (shown in Fig. 4). This geometric drawing is found on sea charts displayed inside the museum. This geometric 2D diagram is the basis for the structural mesh. A light-emitting diode, with variable color and intensity, is placed at the intersection of the structural subelements. The cupola's structural mesh reads as a fine line drawing against the sky, and becomes a powerful scenographic instrument and a symbolic hemisphere.

\section{Physical Numerical Form and Its Analysis}

Starting from this geometric 2D mesh pattern, an exact 3D shell surface needs to be developed that will hold the shell. The material choice for the skeletal shell is set to steel (taking both compressive and tensile loads). The existing situation imposes the contextual boundary conditions.

- The shell's height cannot appear above the historic building's ridge.

- The courtyard façades can only carry additional vertical loads.

- Any horizontal loads can only be resisted by the four courtyard corners.
The loxidrome 2D map is scaled to the inner courtyard dimensions. One quarter of this $2 \mathrm{D}$ grid is modeled with structural elements that have both compressive and tensile load bearing capacity but no bending stiffness. The idea behind the form-finding process is to develop a hanging chain model with only axial loaded members.

The nodes at the boundaries (façades) are restrained in the vertical direction but allowed to move in the direction perpendicular to the façade. The four corner nodes are pinned in all directions. At the intersection of the nodes, the gravity loads caused by the self-weight of the steel members and glass covering is modeled; this load value differs for most nodes because of the complex 2D geometry of the initial pattern.

An adapted version of the dynamic relaxation method with kinetic damping, which takes into account the contextual boundary conditions, performs the form-finding. Summarized, the dynamic relaxation technique traces step-by-step for small time increments $\Delta t$ the motion of each interconnected node of the grid until the structure comes to rest in static equilibrium. The motion of the grid is caused by applying a negative fictitious gravity tributary load at all the grid nodes. The upwards load avoids having to turn the structure upside down to get the hanging tension form. During the form-finding process, the values of all numerical quantities (elastic stiffness $E A$, bending stiffness $E I$, and load) are arbitrary because it is only their ratios that effect the shape. The dynamic relaxation formulation for this project uses Newton's second law governing the motion of any node $i$ in direction $x$ at time $t$

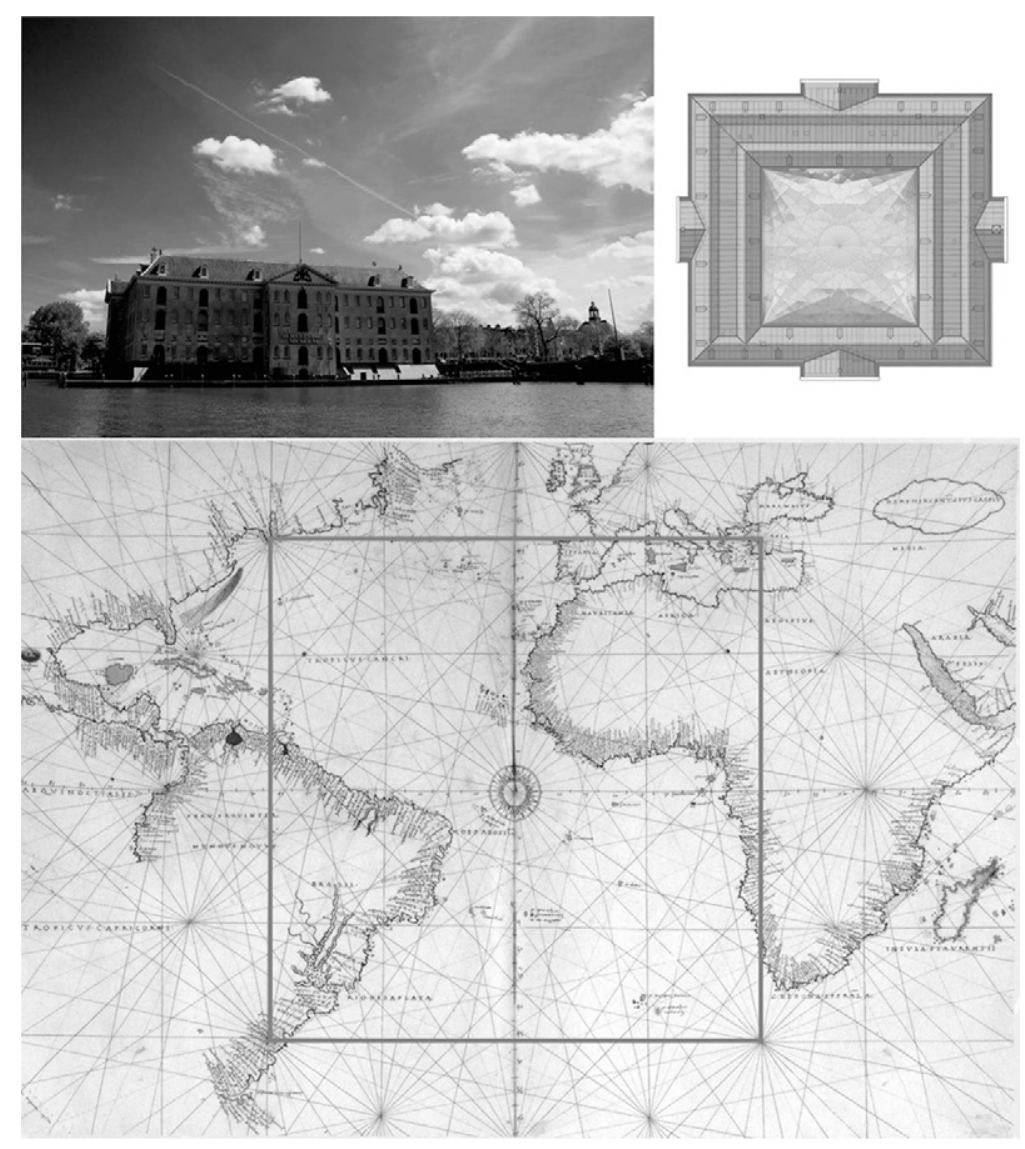

Fig. 4. The square courtyard of the NSA is covered by a steel glass structure whose irregular mesh is based on a loxidrome map with 16 wind roses (top left photograph courtesy of Hella Bauman, reprinted with permission) 


$$
R_{i x}^{t}=M_{i} \dot{v}_{i x}^{t}
$$

where $R_{i x}^{t}=$ residual force at node $i$ in direction $x$ at time $t ; M_{i}=$ lumped mass at node $i$; and $\dot{v}_{i x}^{t}=$ acceleration at node $i$ in direction $x$ at time $t$.

Expressing the acceleration term in Eq. (1) in finite difference form and rearranging the equation gives the recurrence equation for updating the velocity components

$$
v_{i x}^{t+\Delta t / 2}=\frac{\Delta t}{M_{i}} R_{i x}^{t}+v_{i x}^{t-\Delta t / 2}
$$

Hence, the updated geometry projected to time $t+\Delta t / 2$

$$
x_{i}^{t+\Delta t}=x_{i}^{t}+\Delta t v_{i x}^{t+\Delta t / 2}
$$

Eqs. (2) and (3) apply for all unconstrained nodes of the grid in each coordinate direction. These equations are nodally decoupled, in the sense that the updated velocity components are dependent only on previous velocity and residual force components at a node. They are not directly influenced by the current $t+\Delta t / 2$ updates at other nodes. Having obtained the complete updated geometry, the new link forces can be determined and resolved together with the applied gravity load components $P_{i x}$ to give the updated residuals

$$
R_{i x}^{t+\Delta t}=P_{i x}+\sum\left(\frac{F}{L}\right)_{m}^{t+\Delta t}\left(x_{j}-x_{i}\right)^{t+\Delta t}
$$

for all elements $m$ connecting to $i$, where $F_{m}^{t+\Delta t}=$ force in member $m$ connecting node $i$ to an adjacent node $j$ at time; and $L_{m}^{t+\Delta t}=$ current length of member $m$ at time, calculated using Pythagoras's theorem in three dimensions.

This process is continued, cycle by cycle, to trace the motion of the structure. So far, no damping has been introduced and, thus, the grid continues to oscillate. This phenomenon can be prevented by introducing "kinetic damping" in all the velocities that are set to zero when a kinetic energy peak is detected. This process will never truly converge, but once the residual forces are measured in, for example, thousandths of Newtons, convergence has occurred for all practical purposes. At that point, a shape is found that is in static equilibrium and that holds the "correct" spatial surface.

This form-finding process yields a 3D cupola with a height of $4.5 \mathrm{~m}$, as shown in Fig. 5 (ratio height/span $=4.5 / 34=1 / 7$ ). The steel skeletal shell mainly works in compression under self-weight. As to be expected, large tensile forces arise in the ring beam framing the shell. The structural elements radiating out from the corners experience the largest compressive forces. Although all boundary nodes can transmit vertical forces onto the façades, the largest vertical reactions are found at the courtyard corners. This clearly shows that the boundary zones of the shell itself acts as truss along the boundary walls.

After the numerical form-finding process, the resulting, generated geometry of the shell is subjected to a nonlinear analysis. The real values of elastic and bending stiffness need to be used during the structural analysis of the grid shell, the results of which are verified against the Building Codes (European Committee for Standardization 1990, 1991, 1993). In the structural analysis, the shell is subjected to the loading combinations of self-weight (glass $0.5 \mathrm{kN} / \mathrm{m}^{2}$, aluminum profile $0.02 \mathrm{kN} / \mathrm{m}$, and steel profile in function of cross-sectional area steel density $78.5 \mathrm{kN} / \mathrm{m}^{3}$ ), live load $\left(0.5 \mathrm{kN} / \mathrm{m}^{2}\right)$, maintenance load $\left(1 \mathrm{kN} / \mathrm{m}^{2}\right)$, impact load $(1.5 \mathrm{kN}$ over
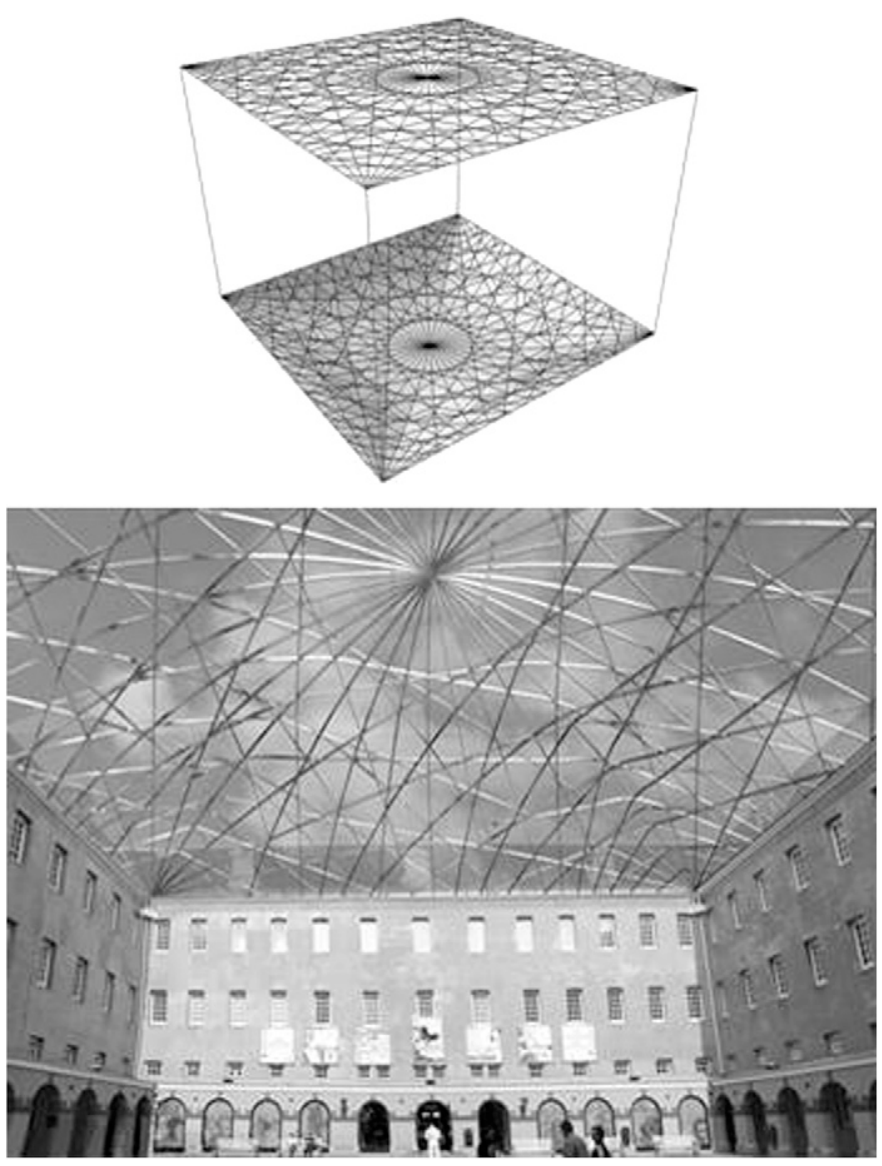

Fig. 5. The shape of the shell is form-found to achieve membrane action

an area of $10 \times 10 \mathrm{~cm})$, thermal load $\left(\Delta T=+22.5^{\circ} \mathrm{C} /-17.5^{\circ} \mathrm{C}\right)$, snow load (varying between 0.84 and $1.12 \mathrm{kN} / \mathrm{m}^{2}$ ), and wind load (varying between -1.57 and $-0.73 \mathrm{kN} / \mathrm{m}^{2}$ ). Because the cupola should express a clarity of form resembling a fine line drawing against the sky, all 3368 elements are dimensioned as steel sections with widths of 40 or $60 \mathrm{~mm}$ and with variable height (100-180 $\mathrm{mm}$ ). The total weight of the steel roof is $100,000 \mathrm{~kg}$, and the ring beam weighs $40,000 \mathrm{~kg}$. The largest ultimate limit state axial forces occur in the grid diagonals (compressive force $940 \mathrm{kN}$ ) and edge beam (tensile force 2,600 kN). A static analysis shows that all elements are loaded far below their critical buckling load by a factor of 2. The maximum shell deflection is $170 \mathrm{~mm}$. The deflection values under wind loadings are relatively small because of the suction effect. A dynamic analysis finds an eigenfrequency value of $2.46 \mathrm{~Hz}$. The different analyses show that the shell satisfies all structural criteria.

The glass cladding has two layers: one bottom layer with two panes of 6-mm half toughened glass and one top layer of 8-mm toughened glass. The issue of facet planarity needed for glass panes imposes a slight modification of the form found geometry of the shell. For this project, a specific method based on origami folding was derived and will be discussed next. Sometimes, planarity of mesh might not be desired (e.g., Foster and Partners' design for the Smithsonian Institute). Because of steel digital fabrication techniques [pioneered in the design of the roof over the great courtyard of the British Museum (Barnes and Dickson 2000)], standardization of meshes and, thus, elements and nodes, is no longer considered crucial, but mesh planarity of nontriangular meshes is still a vital issue. 


\section{Construction Constraints Adapt the Irregular Faceted Catenary Surface}

In this project, the plan geometry of the roof is based upon Fig. 6, in which 16 equally spaced points around a circle are all joined by a total of 120 straight lines. The square plan of the roof itself (Fig. 6) is the central square part of the circle with only the four corner points remaining from the original 16.

Thus, one can calculate $\left(x_{i}, y_{i}\right)$, the plan coordinates of the $i$ th vertex at which two lines cross. Then, the heights of the nodes, $z_{i}$, need to be calculated so that all of the glass facets are flat, although the shape of the structure is dome-like, as shown in Fig. 5. Clearly, this is only
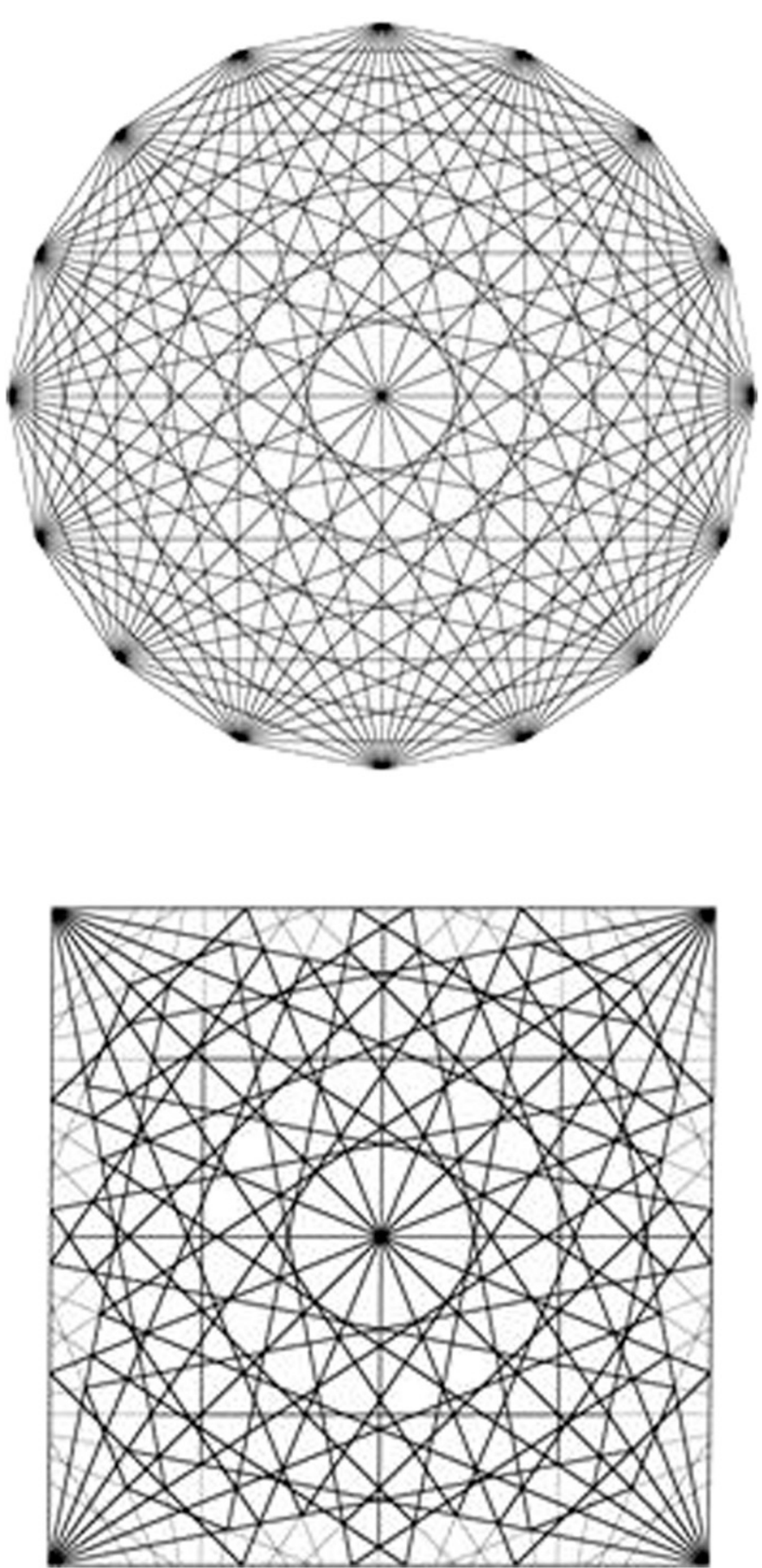

Fig. 6. Plan geometry of the roof a problem for facets with four or more sides because a flat triangle can always be constructed with three arbitrary vertices.

\section{Formulation of the Problem}

It is supposed that the equation describing the $j$ th flat facet is

$$
z=a_{j} x+b_{j} y+c_{j}
$$

If the $i$ th vertex is on the $j$ th facet

$$
z_{i}=a_{j} x_{i}+b_{j} y_{i}+c_{j}
$$

To get the faceted surface to form the dome, it needs to be pulled toward the desired shape. Imagine that the dome was connected to vertical springs at each vertex, such that the tension in each spring is equal to

$$
s_{i}\left[z_{i}-f\left(x_{i}, y_{i}\right)\right]
$$

The spring stiffness, $s_{i}$, is chosen to be proportional to the plan area in the region of the $i$ th vertex. This will have the effect of pulling the roof toward the form

$$
z=f(x, y)
$$

For the NSA roof, $f(x, y)$ was chosen such that

$$
\begin{aligned}
\frac{\beta}{z}= & \sqrt{\frac{1}{(L-x)^{2}}+\frac{1}{(L-y)^{2}}}+\sqrt{\frac{1}{(L-x)^{2}}+\frac{1}{(L+y)^{2}}} \\
& +\sqrt{\frac{1}{(L+x)^{2}}+\frac{1}{(L-y)^{2}}}+\sqrt{\frac{1}{(L+x)^{2}}+\frac{1}{(L+y)^{2}}}
\end{aligned}
$$

in which $\beta$ is a constant, $2 L=$ the side length of the square, and the origin of coordinates is at the center of the square. Thus, the mathematical problem of minimizing the strain energy function is

$$
U=\frac{1}{2} \sum_{i=1}^{\text {last vertex }} s_{i}\left[z_{i}-f\left(x_{i}, y_{i}\right)\right]^{2}
$$

subject to the constraints

$$
z_{i}=a_{j} x_{i}+b_{j} y_{i}+c_{j}
$$

for each vertex of each face. The solution was found using Lagrange multipliers. The Lagrange multipliers can be considered as the vertical forces that the facets apply to the vertices to prevent the facets becoming bent by the vertical springs.

\section{Maxwell Reciprocal Diagram}

The problem of finding flat facets to approximate a curved surface is identical to that of finding tensions in a plane prestressed network. This may be a useful concept, in that it is easier to imagine forces in a flat network than folds in a surface. The reason that the two problems are identical is based upon the following reasoning.

Imagine that the $z$ coordinate of the faceted surface represents an Airy stress function (Timoshenko and Goodier 1970), $\phi$. The corresponding plane stresses are 


$$
\begin{gathered}
\sigma_{x}=-\frac{\partial^{2} \phi}{\partial y^{2}} \\
\sigma_{y}=-\frac{\partial^{2} \phi}{\partial x^{2}} \\
\tau_{x y}=+\frac{\partial^{2} \phi}{\partial x \partial y}
\end{gathered}
$$

The curvature of the surface is zero on the facets and concentrated in the folds between them. Thus, there is no stress in the areas of the facets and a concentration of stress at the folds. This corresponds to a plane, horizontal prestressed network of struts and ties. Because the dome is convex to the outside, the folds on the surface are ties, and the upwards folds from the horizontal around the boundary are struts. Thus, the problem of finding flat facets is mathematically identical to finding states of prestress in a plane network of struts and ties. The state of stress in a network can be represented graphically using the reciprocal network proposed independently by James Clerk Maxwell and W.P. Taylor (Timoshenko 1953; Timoshenko and Young 1965). In the United Kingdom, the technique is associated with Bow's notation and on continental Europe with Cremona (Cremona 1879). Fig. 7 shows the reciprocal network applied to the tensions and compressions corresponding to the folds in Fig. 6. The length of a line represents the change in slope between two facets. Figs. 8 and 9 are simplified versions of Figs. 6 and 7, respectively, and are used to demonstrate how to read the preceding figures. Imagine that Fig. 8 is a plan view of a pyramid. Regions A, B, C, and D are the sloping triangular facets, and $\mathrm{E}$ is the surrounding flat ground. There are four convex folds between the facets, and four concave folds between the facets and the ground. The convex folds correspond to tension diagonals in the analogy, whereas the concave folds are compression elements. Fig. 9 contains the corresponding force polygons. Regions 1 to 5 in Fig. 9 are the force polygons corresponding to nodes $\mathrm{I}$ to $\mathrm{V}$ in Fig. 8. The key to using Bow's notation is to go counterclockwise

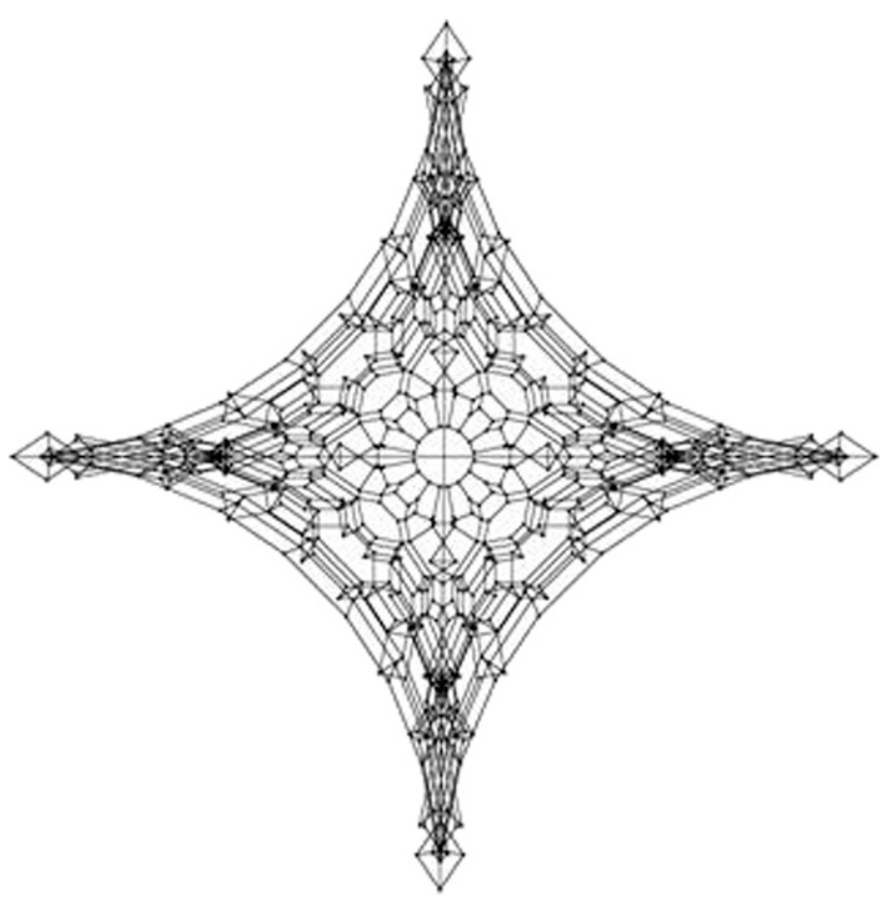

Fig. 7. Maxwell reciprocal network diagram for the shell

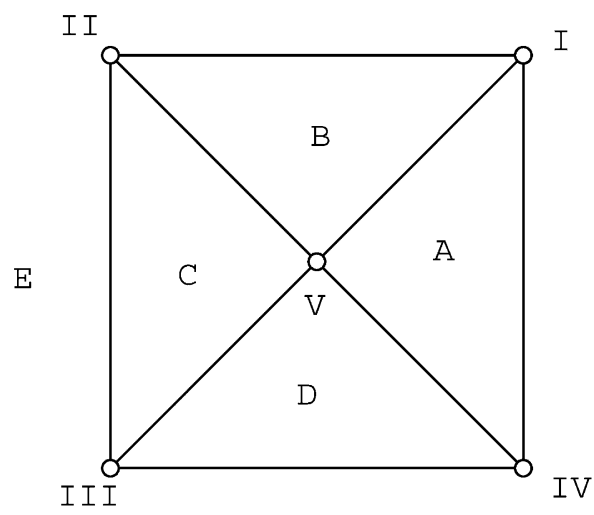

Fig. 8. Plan geometry for a simple pyramid

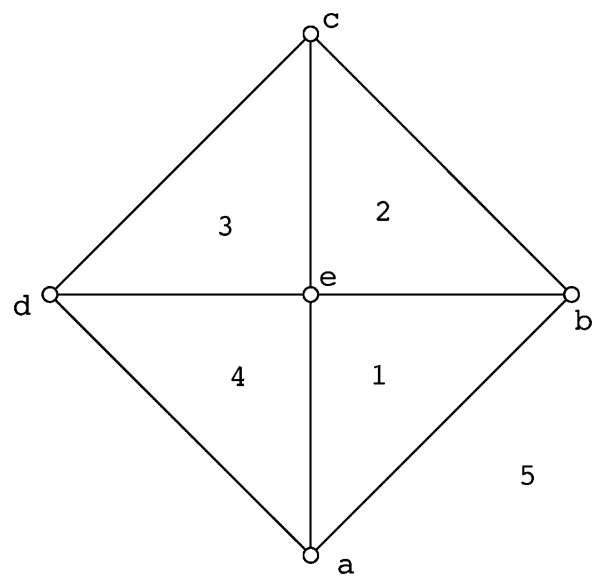

Fig. 9. Maxwell reciprocal network diagram for the pyramid shown in Figure 8

around the nodes in Fig. 8. Thus, going counterclockwise around node IV gives us A-D-E, which indicates that one should go a-d-e around the force polygon in Fig. 9. When interchanging Figs. 8 and 9, the same logic still applies (as it also does between Figs. 6 and 7).

\section{Conclusion}

In 2005, Ney and Partners won the international design competition for a roof over the courtyard of the Dutch Maritime Museum in Amsterdam, which is housed in a monumental former seventeenth century ship gunpowder warehouse. The complex design competition brief stipulated that the new roof should respect the boundary conditions of height restriction and maximum bearing capacity of the existing historic masonry walls. The winning design refers to the symbolism of the admiralship building's history through the grid pattern of the shell. This irregular mesh is based on a series of rosettes with 16 loxodromes, a figure found on historical sea charts. A numerical form-finding technique uses this $2 \mathrm{D}$ mesh as a base and generates a 3D shell shape that has a sculptural quality to it, but one that is exclusively grounded in the rational logic of engineering. The complexity of obtaining planarity in all of the fourand five-sided facets of the irregular meshed skeletal shell is solved in a novel, analytical origami approach based on Maxwell reciprocal diagrams. This structurally efficient and constructible shape shown 


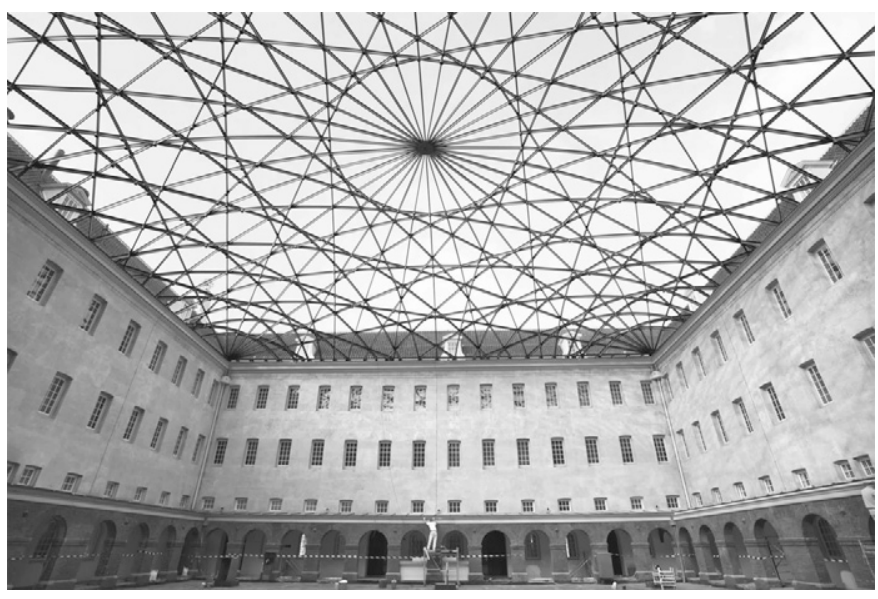

Fig. 10. The realized roof over the courtyard of the Dutch Maritime Museum in Amsterdam (built in 2011) refers to the symbolism of the admiralship building's history through the grid pattern of the shell (photograph from www.MartinWaalboer.nl, reprinted with permission)

in Fig. 10 is unattainable to anyone who attempts to produce this form in an exclusively sculptural, esthetic manner. The designer, Laurent Ney (Adriaenssens et al. 2010; Strauwen et al. 2005), argued that the freedom in generating efficient forms lies in the right selection of the material and boundary conditions, not in adhering to geometric and nonuniform rational B-spline surfaces.

\section{References}

Adriaenssens, S., De Voldere, S., Ney, L., and Strauwen, I. (2010). Laurent Ney: Shaping forces. A+ editions, CIAUD-ICASD, Brussels.

Barnes, M. and Dickson, M. eds. (2000). Widespan roof structures. Thomas Telford, London.

Basso, P., Del Grosso, A., Pugnale, A., and Sassone, M. (2009). "Computational morphogenesis in architecture: the cost optimization of free form grid-shells." Proc., Int. Association for Shell and Spatial Structures (IASS) Symposium 2009 Evolution and Trends in Design, Analysis and Construction of Shell and Spatial Structure, Valencia, IASS, Madrid, Spain.

Billington, D. (2008). The art of structural design: A Swiss legacy, Yale University Press, New Haven, CT, 128-163.

Block, P., and Ochsendorf, J. (2007). "Thrust network analysis: A new methodology for three-dimensional equilibrium." J. Int. Assoc. Shell Spatial Structures, 48(3), 1-7.

Cremona, L. (1879). Le figure reciproche nella statica grafica, Ulrico Hoepli, Milan
Day, A. S. (1965). "An introduction to dynamic relaxation." The Engineer, 29, 218-221.

European Committee for Standardization (CEN). (1990). "Eurocode: Basis of structural design." Eurocode 0, Brussels, Belgium.

European Committee for Standardization (CEN). (1991). "Actions on structures." Eurocode 1, Brussels, Belgium.

European Committee for Standardization (CEN). (1993). "Design of steel structures." Eurocode 3, Brussels, Belgium.

Glymph, J., Shelden, D., Ceccato, C., Mussel, J., and Schober, H. (2004). "A parametric strategy for freeform glass structures using quadrilateral planar facets." Automat. Construct., 13(2), 187-202.

Guillaume, P., Blengini, G., Ruaut, P. and Brunetti, F. (2005). "Nouvelle foire de Milan: prouesses d'acier." Revue Centre Information Acier 8, $20-27$.

Huerta, S. (2003). "El calculo de estructuras en la obra de Gaudi." Ingeniera Civil, 130, 121-133.

Kilian, A. and Ochsendorf, J. (2005). "Particle-spring systems for structural form-finding." J. Int. Assoc. Shell Spatial Structures, 46(148), 77-84.

Kohlmaier, G., and Von Sartory, B. (1991). Houses of glass: A nineteenthcentury building type, MIT, Cambridge, 641.

Leach, N., Turnbull, D., and Williams, C. (2004). Digital tectonics, Wiley-Academy, London.

Moreyra Garlock, M., and Billington, D. (2008). Félix Candela engineer, builder, structural artist, Yale University Press, New Haven, CT

Otto, F., Rasch, B., Pfafferodt, Schonborn, A.G., and Schanz S. (1995). Finding form. Deutsche Werkbund Bayern, Edition Axel Menges, Munich, Germany.

Schek, H. J. (1974). "Force density methods for form finding and computation of general networks." Comput. Methods Appl. Mech. Eng., 3(1), $115-134$.

Schober, H. (2002). "Geometrie-Prinzipien fur wirtschaftliche und effiziente Schalentragwerke." Bautechnik, (79), 16-24.

Shelden, D. (2002). "Digital surface representation and the constructability of Gehry's architecture." Ph.D. thesis, MIT, Cambridge, MA.

Strauwen, I., Ney, L., and Vandevelde, D. (2005). 06/Laurent Ney freedom of form finding. Vai and A16, Antwerp, Belgium.

Timoshenko, S. P. (1953). History of strength of materials, McGraw Hill, New York.

Timoshenko, S. P., and Goodier, J. N. (1970). Theory of elasticity, McGraw Hill, New York.

Timoshenko, S. P., and Young, D. H. (1965). Theory of structures, McGraw Hill, New York.

Williams, C. (2000). "The definition of curved geometry for widespan enclosures." Widespan roof structures, M. Barnes and M. Dickson, eds., Thomas Telford, London, 41-59.

Williams, C. (2001). "The analytic and numerical definition of the geometry of the British Museum Great Court Roof." Mathematics \& design 200, M. Burry, S. Datta, A. Dawson, and A. J. Rollo, eds., Deakin University, Geelong, Victoria, Australia, 434-440.

Woods, M., and Swartz, W. A. (1988). Glass houses: A history of greenhouses, orangeries and conservatories, Aurum Press, London, 216. 